\title{
A NEW INDUSTRIAL ECONOMICS: EXPLORING METHODS OF TRANSACTION COST REDUCTION IN MODERN INDUSTRIES
}

\author{
Armaan Lakhani \\ Vasant Valley School, New Delhi \\ DOI: 10.46609/IJSSER.2020.v05i07.014 URL: https://doi.org/10.46609/IJSSER.2020.v05i07.014
}

\begin{abstract}
With the advent of the $4^{\text {th }}$ industrial revolution, the employment of knowledge workers will constitute a majority of the labour force, as manual jobs are replaced with automation and artificial intelligence. Given the arrival of this fundamental shift in our economy, measuring the productivity of knowledge workers will become the most important point of leverage for businesses, organisations, and indeed, countries. Currently, there exists no universal measure for knowledge worker productivity. Producing such a measure is also difficult, given the situational, cultural and unique nature of knowledge work in different industries and different countries. This paper aims to provide an overview of the issues and strategies that currently underlie the measurement of knowledge worker productivity, and the most important strategies that could be developed in the Indian context. The paper aims to chart a way forward in the field and propose new arenas for research and strategic development.
\end{abstract}

Keywords: Industrial economics, Industrial revolution, Productivity, Knowledge workers

\section{INTRODUCTION}

Industrial economics has become an increasingly relevant field, given the advent of the $4^{\text {th }}$ industrial revolution, and the large scale changes it will bring to the fundamentals of the world's economic system and workforce. The 4th Industrial Revolution is largely driven by four specific technological developments: high-speed mobile Internet, AI and automation, the use of big data analytics, and cloud technology (Change, 2017). Of these four technologies, AI and automation are expected to have the most significant impact on employment figures within the global workforce (Change, 2017).

Therefore, the structure of the economy continues to change; where once they are dependent on the productivity of a manual workforce, companies increasingly depend on the productivity of knowledge workers (Ramirez and Nembhard, 2004). Today, knowledge workers account for 


\section{International Journal of Social Science and Economic Research}

ISSN: $2455-8834$

Volume: 05, Issue: 07 "July 2020"

more than two-thirds of the workforce, and thus should be the focus of strategic plans to improve productivity (Ramirez and Nembhard, 2004). Currently there are no universally accepted methods to measure knowledge worker productivity, or even generally accepted categories (Ramirez and Nembhard, 2004). This is because it is more difficult to measure the productivity of knowledge workers, as opposed to manual labourers for whom a commonly accepted measure exists.

Knowledge workers are those who "think for a living," making productivity challenging to measure (Morley, 2020). According to the U.S. Bureau of Labor Statistics, measuring employee productivity means calculating "output per hour" of work (Morley, 2020). This formula is problematic for measuring knowledge worker productivity, because outputs are intangible and difficult to define, results are often based on team output rather than individual, companies are not necessarily tracking hours for salaried employees, and time spent working is increasingly blurred as a mobile workforce integrates their professional and personal lives (Morley, 2020).

Therefore, measuring knowledge worker productivity is situational, since outputs and how to calculate them varies widely across an organization (Morley, 2020). Traditional measures of output per unit of production like 'calls per agent per hour' or 'units per week' or 'cost per unit'

are inappropriate for Knowledge Based businesses (Workplace Pin, n.d). In fact, they may possibly drive the wrong behaviours and have a potential to destroy the value of organisations (Workplace Pin, n.d). However, it is crucial then to develop at least a broad rubric against which productivity of knowledge workers can be measured, in order for organizations to optimize their processes and produce further employment and ensure smooth operations, which in turn benefits the workers.

This paper will closely examine the issue of measuring knowledge worker productivity in the Indian context, further focusing on industries such as Information Technology and strategic consultancy, which have seen the sharpest rise in knowledge work in India. The paper will provide an overview of theoretical foundations and the evolving strategies and measures that have been developed with respect to knowledge workers. The paper will aim to apply international best practices and understand the unique dynamics of Indian industry, concluding with recommendations for future evaluation.

\section{BACKGROUND}

Historically, the countries and the industries that have emerged as the leaders in the last hundred years in the world are the countries and the industries that have led in raising the productivity of the manual worker - the U.S. first, Japan and Germany second (Drucker, 1999). Fifty years from now, if not much sooner, leadership in the world economy will have moved to the countries and 


\section{International Journal of Social Science and Economic Research}

ISSN: $2455-8834$

Volume: 05, Issue: 07 "July 2020"

to the industries that have most systematically and most successfully raised knowledge-worker productivity (Drucker, 1999). In 1999, Peter Drucker offered a theoretical model for measuring the productivity of knowledge workers (Moon, 2009). In Drucker's model, one can measure the productivity of knowledge workers by tracking two processes. First, how quickly can any worker frame a request for information (interactions or experiences) and get an accurate response (Moon, 2009). Second, how quickly can this worker understand a request and provide an accurate answer (Moon, 2009).

The literature and secondary research currently available on worker productivity have commonly agreed on six factors that correlate to higher levels of knowledge worker productivity - social cohesion, perceived supervisory support or autonomy, continued innovation or information sharing, continued learning towards a clear vision and organizational goals, external outreach and communications, and trust, based on which knowledge workers want to and will choose to work with the organization (Morley, 2020; Worker Pin, n.d). Trust entails that the knowledge worker is both seen and treated as an "asset" rather than a "cost" (Drucker, 1999). It requires that knowledge workers want to work for the organization in preference to all other opportunities (Drucker, 1999). The 6 factors as outlined here have been derived through a scientifically robust review of over 800 research studies (Worker Pin, n.d).

As opposed to the work of a manual workers, measurement of the productivity of a knowledge worker is measured by quality and not quantity. In most knowledge work, quality is not a minimum and a restraint (Drucker, 1999). Quality is the essence of the output. For example, in judging the performance of a teacher, one does not ask how many students there can be in his or her class. We ask how many students learn anything, which is a quality driven question (Drucker, 1999). As an opposite example of manual work, in appraising the performance of a medical laboratory, the question of how many tests it can run through its machines is quite secondary to the question of how many tests results are valid and reliable (Drucker, 1999). Increasingly, the ability of organizations - and not only of businesses - to survive will come to depend on their "comparative advantage" in making the knowledge worker more productive (Drucker, 1999). The ability to attract and hold the best of the knowledge workers is the first and most fundamental precondition.

Organizations have already begun to implement strategies to attempt to harness the productivity of their knowledge workers. Research by McKinsey shows that fully half of all interactions are constrained by one of five barriers: physical, technical, social or cultural, contextual, and temporal (Matson and Prusak, 2010). The following section will elaborate upon these targeted productivity-improvement efforts to increase both the efficiency and effectiveness of the interactions between workers. 


\section{International Journal of Social Science and Economic Research}

ISSN: $2455-8834$

Volume: 05, Issue: 07 "July 2020"

\section{DISCUSSION}

Existing practices and methods used include the following: One remedy implemented by some organizations is to create "communities of practice" for people who could benefit from one another's advice (Matson and Prusak, 2010). The communities feature online tools to help geographically dispersed members search for basic information (say, member roles and the specific challenges they are addressing) and sometimes use the latest social-networking tools to provide more sophisticated information (Matson and Prusak, 2010). Petrobras, the Brazil-based oil major, created a series of case studies focused on real events in the company's past that illuminate its values, processes, and norms. The cases are discussed with new hires in small groups - promoting a better understanding of how the organization works and encouraging a culture of knowledge sharing and collaborative problem solving are sophisticated information, including whom the members have worked or trained with (Matson and Prusak, 2010). To overcome contextual barriers, he US National Aeronautics and Space Administration (NASA), for instance, holds a biannual "Masters Forum" to share knowledge across disciplines (Matson and Prusak, 2010). When it found that researchers didn't have time to share lessons from their experiments, Boston-based Millennium Pharmaceuticals, created a small group of scientists to act as "knowledge intermediaries" to reduce the time needed to make key decisions (Matson and Prusak, 2010).

The Indian context comes with its own specific dynamics, which must entail a requisite change in the way knowledge worker productivity is measured, in a culturally nuanced manner. A large scale survey on productivity and collaboration among Indian knowledge workers, indicated a widespread impact on productivity owing to document-related challenges (YourStory, 2012; Biswas, 2012). The survey findings also indicate a high degree of concern for document security among respondents. Finally, the survey found an overwhelming majority confirming that they expect to increasingly use their smartphones and tablets not just to access but also to create, manage and review documents in the near future (YourStory, 2012; Biswas, 2012). Productivity continues to be a challenge for Indian knowledge workers due to document-related issues like: searching email attachments, copying data from one document format to other, struggling with incompatible document formats, etc (YourStory, 2012; Biswas, 2012). Therefore, in a developing country and lower technological context like in India, it is imperative that organizations and knowledge workers adopt documentation tools that allow them to be productive and collaborative in a highly-secured manner (YourStory, 2012; Biswas, 2012). Given the increasing penetration of mobile devices like smartphones and tablets it is equally important that organizations enable their workforce to create, manage and review content on these devices (YourStory, 2012; Biswas, 2012). 


\section{International Journal of Social Science and Economic Research}

ISSN: $2455-8834$

Volume: 05, Issue: 07 "July 2020"

Culturally driven measures are crucial because the workplace environments will depend on dominant cultural trends in each country. For example, in India, when faced with disabling situations or bosses, Indians generally indulge in behaviors that serve their self-interests, if not leave (Economic Times, 2018). They say what powerful persons want to hear, hide their intentions and behave in socially desirable ways to please others to get undue favors from them (Economic Times, 2018). But they are rarely productive. This is quite harmful for the organization. This creates a mirage of everything going smoothly when it is not. This leads to subsequent downfall of the venture (Economic Times, 2018). By providing the workforce the three necessary tools of autonomy, transparency and nurturance, organizations transform their environment into an enabling one where employees are intrinsically encouraged to set ambitious goals and work diligently to achieve them (Economic Times, 2018).

International best practices for worker productivity maximization must be taken heed of, but imported in a manner that is effective in the Indian context. Harnessing technology is a key measure - IT must be designed to reduce the amount of time knowledge workers spend on information access, management and manipulation and to increase the accuracy of these processes (Mohanta, 2006). Through mobile and wireless technologies, knowledge workers can make use of previously unproductive time, access corporate information as soon as it is needed, and communicate in real-time with colleagues and customers via multiple electronic channels regardless of location (Mohanta, 2006).

\section{CONCLUSION}

Extensive review of the literature indicates that the possibility of measuring the productivity of knowledge work environments is acknowledged, but practical implementation lags far behind (Thomas and Baron, 1994; Zhu and Shibalayeva, 2017). The causes of this lag are based on the perception that knowledge work is unmeasurable and of little significance. However, what is clear is that knowledge work is by far the area where measurement offers the greatest potential benefits (Thomas and Baron, 1994; Zhu and Shibalayeva, 2017). It is more difficult to measure knowledge worker productivity than it is to measure blue-collar worker productivity. This does not mean that knowledge work cannot be measured, but that more innovative measurement techniques are needed (Zhu and Shibalayeva, 2017).

Giving potential and current employees more freedom to work how, when and where can be very beneficial for companies. It can allow them to recruit a global workforce, increase employee loyalty and commitment, scale at a quicker pace and reach new levels of productivity (Change, 2017). Employees benefit too as not having to commute means they will have more free time, a better work-life balance and greater flexibility leading to overall employee satisfaction and commitment (Change, 2017). Implementing an office open setting would allow for further 


\section{International Journal of Social Science and Economic Research}

ISSN: $2455-8834$

Volume: 05, Issue: 07 "July 2020"

information sharing, where team members can readily witness workers (especially leaders) willingly sharing ideas and information (Morley, 2020). It's essential for the organization as a whole, as well as managers at every level, to clearly communicate goals to team members. At the team level, managers need to be mindful of helping individual workers understand how what they do helps both the team and the company to be successful (Morley, 2020).

While there is no universally implemented or accepted measure for knowledge worker productivity, proxy measures could be used by organisations (Worker Pin, n.d). The six factors mentioned above in this paper have been integrated as a survey tool that allows team members to answer a series of 'validated' questions from which a Knowledge Work Productivity Proxy Score KWPPS can be developed for teams (Worker Pin, n.d). Whilst the score is useful as an overall measure of the conditions that propagate Knowledge Worker Productivity, it is most powerful when used with teams to help them assess themselves and determine actions to improve their performance on the 6 factors (Worker Pin, n.d). There is convincing evidence that it is beneficial to set up situationally relevant metrics based on the quantification framework (Zhu and Shibalayeva, 2017). Using a sophisticated quantification framework on site to quantify knowledge worker's productivity would be useful. Measuring from different dimensions will conduct a balanced and fair result (Zhu and Shibalayeva, 2017).

Finally, it is key in the Indian context that there be further research and studies conducted on Indian companies, as the available literature is centered heavily around the Western experience, and case studies are mostly of western companies. Research on Indian companies could be a useful model to be used for other countries in the developing world, which are now moving towards hiring more knowledge workers. With a very high level of youth and outsourcing, India has already been able to train a significant amount of knowledge workers especially in IT (Drucker, 1999; Economic Times, 2018). Therefore, countries with such high populations of youth like India hold the way forward for research and development in this field.

\section{REFERENCES}

Biswas, S, (5 October 2012), 'Indian knowledge workers say document-related issues at work impact productivity: Adobe survey', Economic Times, https://economictimes.indiatimes.com/jobs/indian-knowledge-workers-say-documentrelated-issues-at-work-impact-productivity-adobesurvey/articleshow/16686615.cms?utm_source=contentofinterest\&utm_medium=text\&ut $\underline{\mathrm{m} \text { campaign }=\mathrm{cppst}}$ 
International Journal of Social Science and Economic Research

ISSN: $2455-8834$

Volume: 05, Issue: 07 "July 2020"

Change Recruitment Group, (2017), 'How Will the Fourth Industrial Revolution Impact the Future of Work?'， https://www.changerecruitmentgroup.com/knowledge-centre/howwill-the-fourth-industrial-revolution-impact-the-future-of-work

Drucker, PF, (1999), 'Knowledge-Worker Productivity: The Biggest Challenge', California Review of Management, Vol.41, No.2, Reprint Series

Economic Times, (26 May 2018), 'Three things to boost the productivity of your knowledge workforce', https://economictimes.indiatimes.com/small-biz/hrleadership/leadership/three-things-to-boost-the-productivity-of-your-knowledgeworkforce/articleshow/64330553.cms?utm_source=contentofinterest\&utm_medium=text \&utm_campaign=cppst

Matson, E and Prusak, L, (2010), 'Boosting the productivity of knowledge workers', McKinsey Quarterly, $\quad$ https://www.mckinsey.com/business-functions/organization/ourinsights/boosting-the-productivity-of-knowledge-workers\#

Mohanta, GC, (2006), 'Strategies for Improving Productivity Of Knowledge Workers - An Overview', Strength Based Strategies, http://citeseerx.ist.psu.edu/viewdoc/download?doi=10.1.1.471.8385\&rep=rep1\&type=pdf

Moon, M, (2009), 'Knowledge Worker Productivity', Journal of Digital Asset Management, Vol.5, 178-180

Morley, I, (2020), 'Measuring knowledge worker productivity is situational', Serraview, https://serraview.com/how-do-you-measure-knowledge-worker-productivity/

Ramirez, Y and Nembhard, D, (2004), 'Measuring knowledge worker productivity: A taxonomy', Journal of Intellectual Capital, https://www.emerald.com/insight/content/doi/10.1108/14691930410567040/full/html

Thomas, B, and Baron, J, (1994), 'Evaluating Knowledge Worker Productivity: Literature Review', USACERL Interim Report, https://apps.dtic.mil/dtic/tr/fulltext/u2/a283866.pdf

Workplace Performance Innovation Network (Pin), (n.d), 'The 6 Factors of Knowledge Worker Productivity that Change Everything', https://www.advanced-workplace.com/wpcontent/uploads/2015/04/6 Factors Paper.pdf

YourStory Team, (6 October 2012), 'Productivity, A Huge Challenge for Indian Knowledge Workers- $52 \%$ Spend 1/4th of Time Managing Documents [Report]', 
International Journal of Social Science and Economic Research

ISSN: 2455-8834

Volume: 05, Issue: 07 "July 2020"

https://yourstory.com/2012/10/productivity-a-huge-challenge-for-indian-knowledgeworkers-52-spend-14th-of-time-managing-documents-report

Zhu, J and Shibalayeva, S, (2017), 'How Can You Measure the Productivity of Knowledge Workers?', Cornell University ILR School, https://digitalcommons.ilr.cornell.edu/cgi/viewcontent.cgi?article=1156\&context=student 